\title{
FOTOGRAFIA E HISTÓRIA, A EXISTÊNCIA E O VESTÍGIO REMANESCENTE: CORPOS NEGROS DE MULHERES NO 'TEATRO DE ENUNCIADOS' DO BRASIL OITOCENTISTA
}

\author{
Maria Elizabeth Ribeiro Carneiro*
}

RESUMO: Rever e refletir sobre fotografias, discursos e memórias construídas no Brasil oitocentista é o objetivo desta abordagem. Exercitar a descrição de imagens de corpos negros de mulheres é oportunidade para se problematizar marcas de sexo-gênero, raça-etnia e condição civil/servil que os localizam (e viabilizam) na sociedade. São marcas que os atrelam a seus destinos biológicos e à dinâmica da ordem escravocrata, possibilitam perceber sentidos historicamente construídos em traços e espessuras, e discutir molduras do pensamento. Problematizar fotografias de corpos negros no/do feminino no oitocentos é parte de um projeto de análise baseado em teorias feministas e na metodologia da "desconstrução", tomada como exercício crítico da historiografia e da cultura, para buscar a reconstrução objetos/sujeitos/subjetividades/discursos outras histórias.

Palavras-chave: história; fotografia; mulheres escravizadas; mães pretas.

\begin{abstract}
To think about discourses and memories of nineteenth century Brazilian society is the aim of this paper. Approach the performativity of black female bodies in photography is an opportunity to discuss about sex-gender, race-ethnic marks and civil/servil condition, and to think about historical inequalities. Marks, traces, signs constitute their figures that seem to be attached to a biological destiny within dynamics of slavery. Re-reading some of them, we can approach to violent experiences and discuss historical frames of reading and thinking. The analysis on black female bodies' photographs is part of a researching project based on feminist theories and deconstrution as a method to see critically discourses, historiography and culture. Also, an attempt to rebuild objects, subjects, subjectivities and discourses in other terms.
\end{abstract}

Keywords: History; photography; enslaved women; black mothers.

O discurso social no Brasil oitocentista produziu o corpo negro em múltiplos suportes da comunicação. Não apenas na forma textual, mas em desenhos, pinturas, caricaturas, vinhetas, fotografias. Eles aparecem em jornais, em anúncios de compra, aluguel e venda, em avisos de fuga, em documentação da administração pública, da literatura e da ciência, como efeitos e instrumentos de discursos que configuram o ordenamento da cidade, da população e do país que

\footnotetext{
* Doutora em História pela Universidade de Brasília, Professora Adjunta do Instituto de História e do Programa de Pós-Graduação em História da Universidade Federal de Uberlândia INHIS / UFU, participa dos grupos de pesquisa GEFEM (Grupo de Estudos Feministas / Universidade de Brasília/UnB/DF), NEGUEM (Núcleo de Estudos de Gênero/Universidade Federal de Uberlândia/UFU/MG), e do LEDDES (Laboratório de Estudos das Diferenças e Desigualdades/Universidade do Estado do Rio de Janeiro/UERJ). mariaercarneiro@gmail.com
}

Dossiê Transversos: O Corpo na História e a História do Corpo, Rio de Janeiro, v. 05; n. 05; Ano 02. dez. 2015. 
se tornara independente. $\mathrm{O}$ poder, a disciplina, o desejo de ordem, decifração e de verdade se exprimem nesses textos que procuram identificar a sociedade - quem somos? E, para isso, buscam esquadrinhar os corpos, os gestos, em seus menores detalhes. Tais imagens naquela realidade dos trópicos, por sua vez, veiculam experiências modeladas em diferentes olhares que, observados sob a perspectiva da história, exibem a intenção ordenadora da sociedade escravocrata. Paisagens mais ou menos estranhas ou exóticas para alguns, ou naturalizadas para outros, na ambivalência das imagens retratadas, não é possível deixar de reconhecer a mirada eurocêntrica e o desejo de civilização.

Corpos de mulheres negras aparecem definidos como elementos das/nas relações da escravidão. Imagens desses corpos são visíveis no campo e nas cidades, nas ruas, nos lares, no cotidiano. Corpos vistos como mercadorias-patrimônio-propriedades representam bens, trabalho e riqueza, e fazem operar dinâmicas políticas, econômicas, simbólicas e sociais. As inúmeras imagens, textuais e iconográficas de mulheres negras no Brasil do século XIX coletadas remetem a diferentes funções e situações, no entanto apontam para uma mesma esfera de localização e para um regime de dominação social - as relações escravistas -. Mulheres negras naquele tempo e lugar costumaram ser vistas como corpos cativos, ou seja, corpos disponíveis que se possuem, disponíveis para a apropriação, corpos que se compram, vendem, alugam, transferem. Corpos que se usam e que, no seu des-valor específico, significam poderes e prazeres em circulação.

Trabalhadores, exóticos, seduzidos, sedutores, esses corpos se replicam nos textos e, no feminino, parecem significar um objeto singular que, em certos enunciados insistentes, apontam tanto para a organização quanto para a desorganização da família. Em suma, eles aparecem em práticas e localizações que conotam a inferioridade do cativeiro, portanto, habitam regiões de sombra, desprestígio ou quase silêncio na paisagem social. Por outro lado, servem como uma espécie de suporte daquilo que se quer iluminar (em relação ao que se quer esconder), na cena que se quer dar a ler (para não expor o que se quer evitar falar). Como coadjuvantes e objetos do poder escravista, as imagens revelam o movimento desses corpos que transitam nos mercados, nas ruas, nos lares, inclusive nos ateliers de fotógrafos e artistas. Particularmente na série que escolhemos analisar, eles aparecem alinhados, enfeitados, enfatiotados, iluminados, em suma, bem comportados, de acordo com o que devem afirmar e significar. Eles exibem a família e reafirmam a propriedade e, nessa condição, superexpostos, definem o lugar social dos que os possuem. Aparecem geralmente sem nome, sem sobrenome, às margens da história.

Silenciados, inquietam o olhar de observadores do presente por habitarem regiões sombrias do discurso. Calados, falam dos poderes do patriarcado escravocrata em operação: das

Dossiê Transversos: O Corpo na História e a História do Corpo, Rio de Janeiro, v. 05; n. 05; Ano 02. dez. 2015. 
relações políticas, econômicas, da reprodução do trabalho e social, de prazeres desregrados ou desmedidos, da mestiçagem, da bastardia, do "ventre livre”. Livre? Nas imagens eles aparecem marcados pela cor da pele, pela diferença sexual, pela localização do cativeiro. Assim, demarcados, rasurados, podem parecer aparentemente resignados. Ainda que acomodados nas imagens, e às margens do discurso social e oficial, e da nação que se quer edificar, eles estão ali. Reunidos como objetos desse discurso, eles reaparecem como objetos-sujeitos de muitas memórias soterradas, subjugadas, sorrateiras, bem ou mal guardadas. Seus olhares não foram apagados e se insinuam como testemunhos de uma experiência que não é possível esquecer ${ }^{1}$.

\section{Antonio e a ama-de-leite. A existência e o vestígio remanescente.}

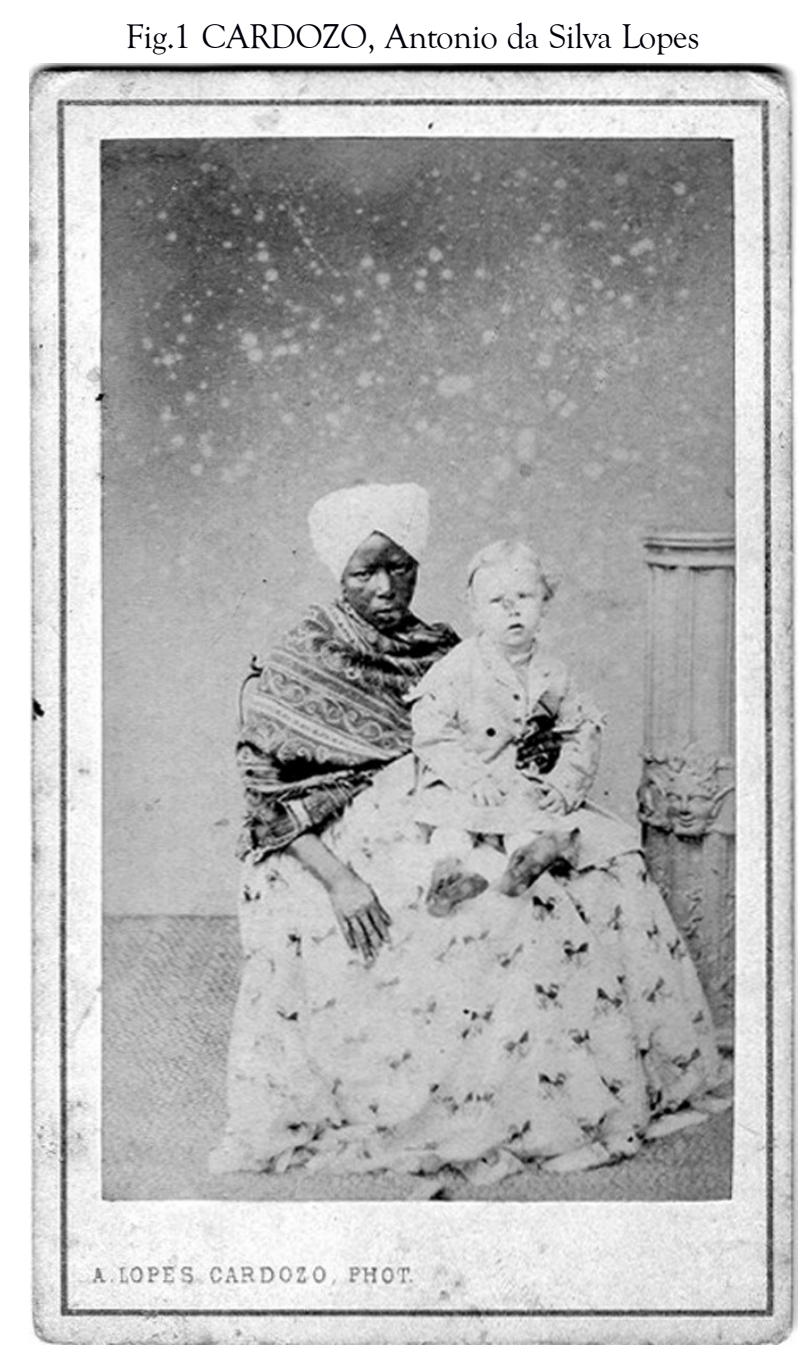

Carte de visite, $6,3 \times 10 \mathrm{~cm}$, Arquivo Nacional Antônio da Costa Pinto com sua ama-de-leite, c. 1861

O cartão de visita tem rasuras e falhas. O papel traz marcas de mofo e respingos do tempo, que preferimos não alterar com o uso de artifícios tecnológicos do nosso tempo. Embora

1 Uma primeira versão do texto foi discutida na Oficina: O Corpo na História e a História do Corpo, promovida pelo LEDDES / Linha de Pesquisa Vulnerabilidades e Controle Social. PPGHIS/UERJ / Campus Maracanã, em 22/09/2014.

Dossiê Transversos: O Corpo na História e a História do Corpo, Rio de Janeiro, v. 05; n. 05; Ano 02. dez. 2015. 
possa ser tomada como objeto de observação, de encenação e leitura do mundo, objeto de consumo e, também, como instrumento de operação disciplinar, a fotografia traz uma imagem clara de seu referente. Roland Barthes assinala: "a fotografia é uma evidência intensificada, carregada, como se caricaturizasse, não a figura do que ela representa (ela é exatamente o contrário), mas sua própria existência” (BARTHES, 1980: p.168).

Ainda segundo o filósofo, a foto-retrato é um campo cerrado de forças, onde os imaginários se cruzam, afrontam e deformam (ID., IBID.: 27) Assim ele se refere à dimensão espectral da fotografia, lugar do encontro e superposição de imaginários: a imagem do sujeito, aquela que o sujeito imagina exibir, a que o fotógrafo imagina capturar, a imagem de que o fotógrafo se serve para exibir sua arte. Acrescentam-se ainda os estratos possíveis da imaginação dos leitores e diferentes tempos, lugares e condições de leitura. Nessa pluralidade imaginária, as fotografias de amas com crianças remetem a certos sujeitos que existiram, porquanto a foto é literalmente uma emanação do referente (ID., IBID.: p.121) e, assim, elas sinalizam para uma serventia: a construção de uma memória familiar, a construção de uma tradição e de uma história.

Naquele tempo e lugar sob o regime da monarquia escravocrata do Brasil oitocentista, muitas famílias proprietárias procuravam uma distinção ao fotografar seus filhos, exibindo com eles suas escravas amas-de-leite. Essas figuras, mais tarde, já na República, seriam objeto da memorialística, e da literatura, e incorporadas ao imaginário social brasileiro como "mães pretas". A produção das imagens de crianças, ainda no oitocentos, sobretudo de varões, parecia não prescindir do suporte humano significante da situação econômica e simbólica da família e seu status social. É visível o desejo de que essas imagens fossem retratadas, exibidas, distribuídas em álbuns e nas paredes do lar, mas também legadas à posteridade.

As colunas clássicas, os tecidos importados, as roupas fartas, os fundos falsos e pintados, e também as amas-de-leite eram objetos que compunham a paisagem mediante a qual as famílias buscavam representar-se e exibir sua condição superior vinculada à propriedade. Esse cartão de visita que chega ao alcance de nosso olhar sugere que a imagem foi distribuída em Salvador da década de 60 e trilhou caminhos insuspeitados, despejando seus sentidos. Volto os olhos à fotografia para refletir, com Barthes, como essa imagem repete mecanicamente o que nunca mais poderá repetir-se existencialmente. Nela, o acontecimento jamais sobrepassa para outra coisa (ID. IBID: 13).

Antonio e sua ama-de-leite, estáticos, olham para a câmera e trespassam as janelas do tempo. A mulher negra e a criança branca olham e, em sua imobilidade e silêncio, sugerem 
refletir sobre o sentido das cores, das formas e das diferenças em seus corpos; sobre os sentidos que se imprimem neles, dando a ler certas qualidades no jogo de uma assimetria. Entre valores e desvalores, aqueles são olhares que estão dentro de regras, mas também fogem aos códigos que lhes conferem inteligibilidade e reativam o enigma do momento único, da existência única, o fantasma de suas aventuras, sua contingência e sua singularidade. Como assinala Barthes, a fotografia propicia um encontro de olhares e imaginários em um não-lugar nas profundezas do tempo existencial, ou um extra-campo sutil.

Ela é um certificado de presença da ama-de-leite e, nesse sentido, não fala forçosamente daquilo que não é mais, mas apenas e com certeza daquilo que foi, atestando que o que vemos de fato existiu (ID., IBID.: 123-7). Os olhares da ama negra e da criança branca são um espetáculo sem nome. Seus olhos escapam às grades do tempo naquela relação amorosa ou fúnebre. Segundo ele,

\section{(...) a fotografia sempre traz consigo seu referente, ambos atingidos pela mesma imobilidade amorosa ou fúnebre, no âmago do mundo em movimento: estão colados um ao outro, membro por membro, como o condenado a um cadáver em certos suplícios. (ID., IBID.: 15)}

A óleo, aquarela, litografia, fotografia ou em palavras, as imagens das amas-de-leite representam o espetáculo, o teatro político das imagens e das sombras e o retorno de olhares, entranhados na dramaturgia da histórica. Nessa reiteração discursiva, entre séries e imagens que se replicam e propagam dando a ler a sociedade em formação ou configuração, o conjunto de imagens assinala aspectos da singularidade do projeto de sociedade brasileira e, também, o esforço em construir uma materialidade expressiva da modernidade e do progresso civilizador. No interior desse alfabeto, a construção de imagens que revelam a permanência de laços escravistas e de relações de proximidade e dominação no cotidiano da vida doméstica exibe a nação em seu paradoxo.

Ao dar a ler certas demarcações de raça, de gênero, de idade e de posição social, como um código, ele exibe e configura identidades do Brasil monárquico e opera uma assimetria disciplinar dessas figuras, aqui pensadas como

(...) identidades sociais (todas elas e não apenas as identidades sexuais e de gênero, mas também as identidades de raça, de nacionalidade, de classe etc.). Essas múltiplas e distintas identidades constituem os sujeitos, na medida em que esses são interpelados a partir de diferentes situações, instituições ou agrupamentos sociais. (LOURO, 2000: p. 12)

Dossiê Transversos: O Corpo na História e a História do Corpo, Rio de Janeiro, v. 05; n. 05; Ano 02. dez. 2015. 
A reiteração das imagens de amas-de-leite em diferentes situações e suportes da comunicação, portanto, é uma pequena e poderosa parte do exercício de reafirmação de hierarquias e sentidos de dominação, de tradição, de subalternidade, ou submissão, mas também da evidência de resistências que escapam aos gestos impressos em corpos femininos negros e cativos, no domínio da inteligibilidade cultural oitocentista. Em seus talhes enobrecidos, em suas feições particulares, em seus olhares fixos, as imagens dos corpos negros de amas-de-leite, entre outras mercadorias-propriedades, assumem um caráter genérico, uma identidade fixa no jogo iconográfico. Mas é nessa relação de cada discurso com a morte que renasce a história.

Michel de Certeau nos ensina a lidar com as lembranças, com figuras mais ou menos emblemáticas da memória e da história. Assim, a representação de mães-pretas, emerge daquela encenação primitiva apagada, mas ainda organizadora. Por meio de suas imagens teóricas cuidadosamente elaboradas, apreende-se o discurso que não deixa de se articular com a morte que postula, mas que a prática histórica contradiz. Pois falar dos mortos é também negar a morte, e quase desafiá-la. Igualmente, diz-se que a história os "ressuscita" (CERTEAU, 2000: p.56-7). (...) Ela não ressuscita nada. Mas evoca a função outorgada a uma disciplina que trata a morte como objeto do saber e, fazendo isto, dá lugar à produção de uma troca entre vivos...

(...) Esta é a história. Um jogo da vida e da morte prossegue no calmo desdobramento de um relato, ressurgência e denegação da origem, desvelamento de um passado morto e resultado de uma prática presente. Ela reitera um regime diferente, os mitos que se constroem sobre um assassinato ou uma morte originária, e que fazem da linguagem o vestígio sempre remanescente de um começo tão impossível de reencontrar quanto de esquecer. (...) (ID., IBID.)

\section{Corpos negros no feminino em série: dos álbuns de familia às telas da história}
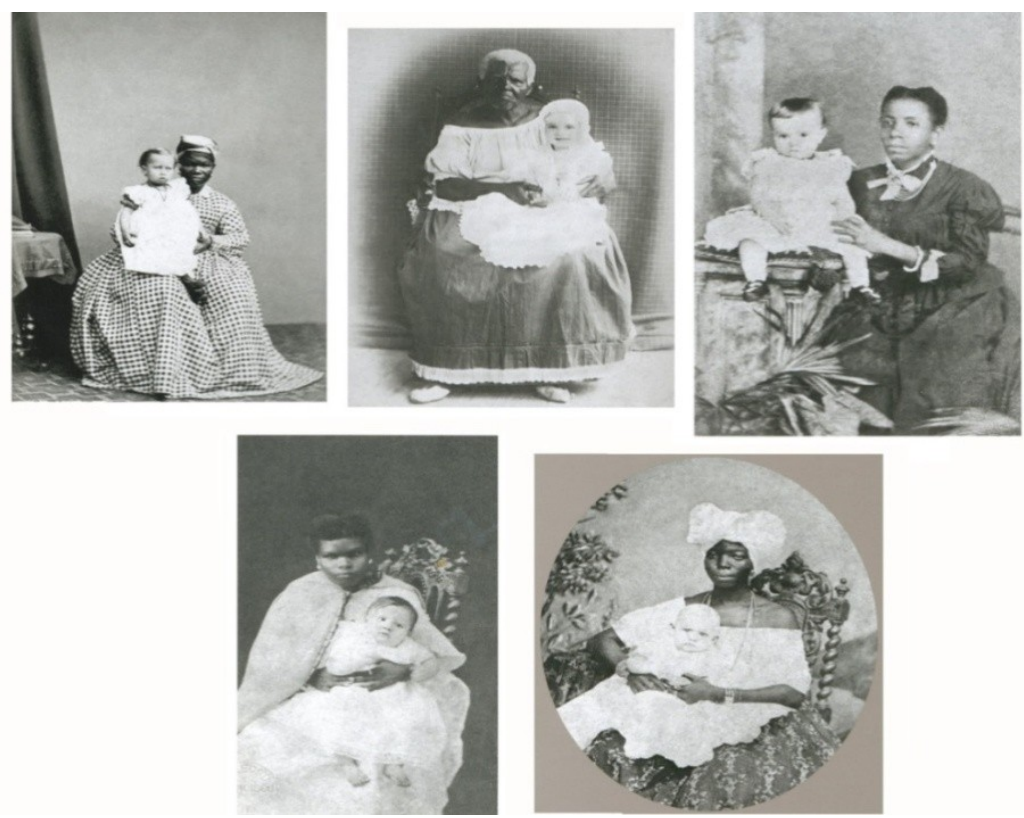

Dossiê Transversos: O Corpo na História e a História do Corpo, Rio de Janeiro, v. 05; n. 05; Ano 02. dez. 2015. 
(Da esq. para a dir.) - Fig. 2. The London Stereoscopic and Photographic Company. Col. Emanoel Araújo. Fig. 3. Fotógrafo não identificado. Col. G. Ermakoff, c. 1890. Fig. 4. Alberto Henschel. FUNDAJ. Fig. 5. Eugênio e Maurício. FUNDAJ. Fig.6. João Goston. IMS, c. 1870.

Mulheres negras jovens, idosas, vestidas como sinhás portuguesas, europeias, ou em trajes africanos ou afro-brasileiros foram retratadas em distintas técnicas de representação visual. Essas imagens circulam no país independente, em uma temporalidade específica - segunda metade do século XIX -, sobretudo nas capitais de província, onde se produzem e exibem as marcas da sociabilidade urbana nascente. Portanto são expressivas da sociedade e da família que se queria dar a ler no ambiente ambivalente dos poderes e das relações sociais escravistas em meio aos desejos de modernidade, ou seja, expõem as condições históricas de sua produção.

Se no início do século XVIII, conforme estudo de Silvia Lara, o bispo do Rio de Janeiro pedia ao rei que todas "as escravas ou livres" ficassem proibidas de sair às ruas após anoitecer sob pena de prisão ou multa pecuniária e, além disso, que fossem proibidas de vestir "sedas, garças, trazerem ouro, mais que as publicamente expostas, porque esses enfeites que vêm em outras, as move piedosamente a imitá-las nos erros" ${ }^{2}$, quase duzentos anos depois, ainda é visível o cuidado com trajes e tecidos para definir lugares e distinções sociais, estes que podem ser lidos como dispositivos de controle e preservação desses sinais. Lara contribui para se observar como funciona a linguagem dos trajes na sociedade portuguesa do Antigo Regime, a partir do conjunto legislativo que, em sua historicidade, orienta em relação à função simbólica do vestuário, sobretudo na localização de nobres e criados (LARA: 2000, 179-180).

O estudo de Lara estabelece diálogos profícuos entre os textos da lei e da norma, relatos de religiosos e viajantes, e a iconografia, que para o período colonial é relativamente escassa. Mas ela se ressente no sentido de que é possivel rastrear apenas olhares masculinos e senhoriais, e sentidos que não são únicos, ficando por decifrar uma infinidade de sinais - enfeites, sedas, inscrições nos corpos, cicatrizes, etc. - ou linguagens no cenário carioca e baiano ainda inacessíveis que tratam de devoções e cultos, crenças, amores, desejos e esperanças (ID., IBID.: 186).

No século XIX, na segunda metade, ao contrário do período colonial, imagens de mulheres negras, inclusive de amas-de-leite ou mães pretas, aparecem como objetos do discurso em profusão. Os fotógrafos chegavam ao Brasil, vindos da Europa e da América do Norte, e também fotógrafos brasileiros montaram seus ateliês para produzir imagens daquela gente e dos traços característicos que identificam a sociedade escravista e a nação dos trópicos. A tecnologia é

2 Carta encaminhada ao Conselho Ultramarino, para parecer de conselheiros, em 20 de setembro de 1702. (LARA, 2000)

Dossiê Transversos: O Corpo na História e a História do Corpo, Rio de Janeiro, v. 05; n. 05; Ano 02. dez. 2015. 
aperfeiçoada rapidamente ao longo daquele século e, do ponto de vista do aprimoramento do suporte da imagem e do processamento físico-químico, os esforços possibilitam a captura, com qualidade, das paisagens cotidianas das ruas e a modelação das encenações portas a dentro, nos ateliês. Há uma produção significativa de imagens da população brasileira, bem como um investimento na distribuição e circulação dessas imagens. Segundo Andrade,

\footnotetext{
a maior parte das cópias fotográficas produzidas em todo mundo entre as décadas de 1850 e 1880 encontra-se em papel albuminado, invariavelmente montado sobre um cartão. Quanto aos formatos, os mais populares naquele período foram o carte-de-visite, o carte-cabinet e o estereograma - este último uma verdadeira coqueluche nos grandes centros urbanos naqueles tempos (ANDRADE, 2004: 6).
}

O aperfeiçoamento da técnica fotográfica acompanha e alimenta, reciprocamente, a ampliação da comunicação. Assim, o movimento de produção de imagens multiplica a capacidade de produção de representações sociais, e sublinha a reiteração de identidades entre signos localizadores dos sujeitos na sociedade. As amas-de-leite, mulheres negras com crianças brancas ao colo, aparecem nos cartes-de-visite como objetos dessa maquinaria discursiva, ou seja, como identidades que são replicadas a fim de povoar e representar com uma conotação emblemática o território da nação. Em diálogo com Foucault, é possível considerá-las como objetos do discurso, isto é, elas não preexistem a si mesmas, retidas por algum obstáculo aos primeiros contornos da luz, mas existem sob as condições positivas de um feixe complexo de relações (FOUCAULT, 2000: p.51).

As relações estabelecidas no interior da família proprietária, proprietária inclusive de mulheres negras, sugerem processos econômicos e sociais, formas de dominação, subordinação, sistemas de normas, técnicas, comportamentos, tensões, acomodações, classificações que não constituem internamente o objeto. Elas definem um campo de exterioridade e revelam as condições que lhes permitem aparecer, justaporem-se a outros objetos, definirem sua diferença ou irredutibilidade. Essa exterioridade expõe, ainda, relações de similitude e inteligibilidade, formando um conjunto de enunciados que configuram uma série. (ID., IBID.)

A série de fotografias em questão sugere um conjunto de imagens inusitadas em outro tempo e lugar, que se tornam recorrentes e naturalizadas naquele tempo e espaço. Ela sugere que se proceda a uma abordagem do ponto de vista do discurso, concebido na metodologia analítica foucaultiana como:

um conjunto de enunciados, na medida em que se apoiem em uma mesma formação discursiva; ele não forma uma unidade retórica ou formal, indefinidamente repetivel e cujo aparelhamento ou utilização poderíamos assinalar (e explicar, se for o caso) na história; é constituído de um número de enunciados para os quais podemos definir

Dossiê Transversos: O Corpo na História e a História do Corpo, Rio de Janeiro, v. 05; n. 05; Ano 02. dez. 2015. 
um conjunto de condições de existência. $\mathrm{O}$ discurso, assim entendido, não é uma forma ideal e intemporal que teria, além do mais, uma história: o problema não consiste em saber como e por que ele pode emergir e tomar corpo num determinado ponto do tempo; é, de parte a parte, histórico - fragmento de história, unidade e descontinuidade na própria história, que coloca o problema de seus próprios limites, de seus cortes, de suas transformações, dos modos específicos de sua temporalidade, e não de seu surgimento abrupto em meio às cumplicidades do tempo (ID., IBID, p.136).

Em suas vestimentas adornadas, engomadas, em saias mais ou menos rodadas, em tecidos mais ou menos rendados ou rebordados, em padrões de xadrez miúdo, em mangas e golas comportadas ou em decotes mais ou menos displicentes, portanto, suas posturas parecem conferir à história uma imagem de naturalidade, isto é, uma mesma imagem, ou como sugere Foucault, um "fragmento de história, unidade e descontinuidade na própria história, que coloca o problema de seus próprios limites, de seus cortes, de suas transformações, dos modos específicos de sua temporalidade”. Daí a importância de se observar seu surgimento em meio às cumplicidades de seu tempo.

Os elementos da imagem - mulheres-cativas-amas pretas e crianças-livres-brancas -, objetos no discurso, não por acaso aparecem em uma mesma pose, e parecem situar-se em um mesmo território de sentidos que não esconde relações de assimetria e desigualdade - de raça, gênero e condição civil. Reaparece, a cada imagem, e é novamente acionado, a cada observação, um conjunto de dicotomias que articulam poderes em operação em suas respectivas duplas significantes. Por sua vez, tal como sugeridas nas imagens replicantes, tais jogos significativos reiterados parecem existir para além da história, de um tempo e lugar específicos, como se fossem testemunhos naturalizados de relações estáticas, documentos ou monumentos de um "passado que estava lá", sempre esteve lá, pronto para ser "registrado" ou "descoberto".

A reiteração da pose na composição, do enquadramento e elementos cênicos provocam, portanto, a ilusão de uma verdade e uma norma naquelas imagens que se pretende pudessem ser fixas, imutáveis, naturais e insuspeitáveis: propriedade-proprietário, preto-branco, mulher-homem, inferior-superior, primitivo-civilizado, mulher cativa-criança (varão) livre... E, assim, naquele período, em linhas gerais, em cenários adornados, imagens comportadas parecem querer contar a história da família brasileira - como se fosse única -, da índole pacífica de um povo - como se não fosse construída, da vocação mais ou menos alegre ou melancólica daquela formação social característica da nação mestiça que se organizava discursivamente em direção ao progresso. Essas imagens foram cunhadas também para demarcar e estilizar a diferença, para atenuar a desigualdade, para difundir relações amenas, conflitos e tensões sociais suavizados por relações “não-violentas" de um modelo docilizado de escravidão nos trópicos. 
Os sentidos maiores se imbricam aos detalhes no alfabeto dos sinais. No mesmo enunciado que desenha e articula o desempenho da dominação patriarcal e escravocrata, as diferenças nos tecidos, decotes, mangas e adornos sinalizam para o caráter híbrido dos signos e dos significados culturais. Tal como observa Said, “todas as culturas estão envolvidas entre si”, já que "nenhuma delas é pura, todas são híbridas e heterogêneas" (SAID, 1993). Assim, o decote exagerado ou a gola rente ao pescoço, a mescla de rendas brancas ou o padrão comportado e geométrico do xadrez miúdo são detalhes que expõem as maneiras distintas de se vestir e compor a encenação da família, que todavia não alteram a forma geral nem a gramática do poder proprietário em operação.

Outra característica dessas imagens reiterativas e recorrentes na coleção que ocupa lugar relevante no imaginário social do Brasil oitocentista exibe a postura das amas e das crianças, esta que foi cuidadosamente composta na cena que deveria ser difundida entre familiares e amigos, ao mesmo tempo informando sobre a ampliação da família, entre suas poses e posses, e reafirmando os limites do círculo da sociabilidade que ela integra. A pose-padrão se inspira em uma composição clássica, braços bem colocados e expostos, as cabeças erguidas, os olhos miram as lentes do fotógrafo. Nesses "cartões de visita", vislumbram-se rostos sérios, olhares vagos, inquietos, inquietados, inquietadores que habitam corpos comportados, ou melhor, constrangidos.

Imóveis, assim materializados, na fixidez de sua composição, de seus contornos, em seus movimentos estudados e fixados pelo fotógrafo, os corpos exibem a performatividade, elaborada por Judith Butler, não como ato singular ou deliberado, mas, em vez disso, como a prática reiterativa e citacional pela qual o discurso produz os efeitos que ele nomeia (BUTLER. In LOURO, 2010: 154-5). Corpos de "ama-de-leite" ou "mãe preta", nesse discurso, se constituem como objetos e sujeitos que aparecem na forma que lhes dá inteligibilidade e viabilidade na cultura, emoldurados pela força que os exclui, inferioriza e a eles confere (e neles reafirma) o lugar social da abjeção. Os cartes-de-visite, fragmentos / expressões da tecnologia moderna que são distribuídas pelas famílias de posses e apontam para o progresso e a civilização, exibem, ao mesmo tempo, e intencionalmente adornadas, embelezadas, cuidadosamente cinzeladas, as zonas inóspitas e inabitáveis da vida social de que fala Butler: zonas, não obstante, produzidas e densamente povoadas por aqueles que não gozam (ou não devem gozar) status de sujeito (ID., IBID.).

Embora não sejam exatamente incomuns as cenas retratadas de mulheres negras aleitando as crianças brancas no Brasil especialmente naquele século, as fotografias que foram

Dossiê Transversos: O Corpo na História e a História do Corpo, Rio de Janeiro, v. 05; n. 05; Ano 02. dez. 2015. 
produzidas e distribuídas para exibir a "família brasileira oitocentista" costumam mostrar essas mulheres negras, geralmente anônimas, em poses semelhantes. Não por acaso, frequentemente, elas trazem os nomes dos fotógrafos, dos ateliês que se tornaram conhecidos, e sobretudo o nome da criança, geralmente o varão, que ocupa o centro da encenação iconográfica e da produção do discurso. Elas nomeiam o elenco que protagoniza a cena, ainda que nela não apareça, ou seja, identificam nomes e sobrenomes de sujeitos livres, masculinos e particularmente daqueles que são proprietários, inclusive daquelas mulheres.

As figuras anônimas, cativas, aparecem em outros veículos da linguagem visual e nos discursos, e exprimem a instituição da família na jovem nação que, ainda escravocrata, pretende se exibir e disseminar de acordo com as tecnologias da modernidade. Enigmáticas, silenciadas, aquelas figuras que se disseminam nas telas da representação fotográfica e habitam uma encruzilhada: local que revela permanências de certos costumes da monarquia escravocrata em meio a anseios de modernidade. Suas imagens exibem poderes do patriarcado que se movimenta e atualiza. Naquelas imagens, o colo de ama cativa negra acolhe o rebento pequeno e branco, pele mais ou menos branca, vestido de branco, proprietário e futuro da nação.

É preciso investigar a produção dessas imagens, sua distribuição e a repartição dos suportes de enunciação e de seus elementos formais - semelhanças, diferenças e classificações -, em relação aos fatos de transmissão, comunicação. A recepção de imagens gera efeitos de realidade. É possível selecionar enunciados, estabelecer essas e outras séries em suas relações (técnicas, econômicas, políticas, estéticas); apreender a coexistência de fatos enunciativos em sucessão, em funcionamento mútuo, ou determinação recíproca. Traçar, em suma, uma gramática de enunciabilidade, visibilidade e uma inteligibilidade de seus componentes em sua materialidade. Por fim, estabelecer diálogos com outras imagens em que os corpos negros no/do feminino são contornados para enunciar modos de objetivação/subjetivação, veicular códigos de comunicação e difundir representações de corpos/identidades no Brasil e no mundo atlântico.

O exercício aqui esboçado é um desafio que sugere des/refazer laços fortes, aparentemente indestrutíveis, entre o passado e o presente, entre as ilusões de sujeitos, referentes, poderes, desejos. Entre categorias e continuidades construídas, entre as palavras e as coisas. Ao modo da arqueologia/genealogia foucaultiana, procuro reunir imagens de mulheres negras e, nelas, com elas, reconhecer as regras que definem não a existência muda de uma realidade, não o uso canônico de um vocabulário, mas o regime político de certos objetos, no caso, corpos negros no feminino. A tarefa aqui desenhada consiste em remetem a conteúdos ou a representações), mas como práticas que formam

Dossiê Transversos: O Corpo na História e a História do Corpo, Rio de Janeiro, v. 05; n. 05; Ano 02. dez. 2015. 
sistematicamente os objetos de que falam. Certamente os discursos são feitos de signos; mas o que fazem é mais articular esses signos para designar coisas. É esse "mais" que os torna irredutíveis à língua e ao ato de fala. É esse "mais" que é preciso fazer aparecer e que é preciso descrever. (FOUCAULT, 2000: p. 56)

Coletar imagens de mulheres negras é também uma forma de pensar sobre a administração da vida, a gestão calculada dos corpos, o controle das populações, entre técnicas de produção da vida e de sua reprodução, da família, da norma, de sexualidades periféricas e/ou polimorfas. A vida aparece e reaparece naqueles corpos imóveis, imobilizados. A vida como objeto político e suporte de poder, instrumento de controle e expressão do sexo, como foco de saber e poder. Quando não visíveis, são imagináveis as resistências...

Se o conjunto dessas imagens exibe um poder normalizador daquela sociedade, que qualifica, mede, avalia, hierarquiza, opera distribuições dentro da norma, elas, em cada região histórica de produção, leitura e recepção, exibem aparelhos e técnicas, não escondem feições singulares de sujeitos históricos em suas objetivações/subjetivações cujas funções são sobretudo reguladoras. Escravocrata, sim, mas sobretudo aquela era também uma sociedade disciplinar, normalizadora, isto é, os dispositivos, discursos e as identidades nela construídas permitem observar instrumentos e efeitos históricos de tecnologias de poder centradas na vida.

Assim, a arqueologia e a genealogia, e particularmente a biopolítica de Foucault sugerem considerar também a distância entre olhares e sentidos que se pretendiam ou não imprimir em cada representação, e o espaço que se estabelece entre as múltiplas leituras que se justapõem e intercalam historicamente, ou seja, entre as condições de possibilidades do discurso de cada imagem ou obra, e também dos discursos de recepção, interpretação e dispersão. Iluminar essas imagens é parte do desafio de re-descrevê-las e observá-las no proscênio de um "teatro dos enunciados" ${ }^{3}$ encenado em telas significativas, localizadas em determinados tempos e lugares...

\section{A familia, o sexo, a raça e a nação modeladas em corpos disponiveis}

Negras, cativas, mulheres. Imagens que exprimem o feminino revestido da pele negra não são neutras ou inocentes. Elas expressam experiências singulares, impregnam o discurso social e despejam sentidos na sociedade do Brasil oitocentista e para além dela. Corpos de mulheres negras, pardas e brancas, cativas, forras e livres emergem em páginas da imprensa, nos estudos da medicina, nos relatos de viajantes, distribuem-se na iconografia, desenhando identidades reconhecidas naquela sociedade que se pretendia ordenar e na nação que se queria construir.

3 A expressão é cunhada por Gilles Deleuze para tratar da metodologia de Foucault, em: DELEUZE, G. FOUCAULT. 2ª ed. Lisboa: Vega, 1998, p. 81.

Dossiê Transversos: O Corpo na História e a História do Corpo, Rio de Janeiro, v. 05; n. 05;

Ano 02. dez. 2015. 
Tais imagens exprimem poderes e desejos de uma realidade que se que se materializava nos discursos de uma "comunidade imaginada" (ANDERSON, 2008), que precisava ser significada e exibida reiteradamente para se afirmar como nação. Não por acaso, após a independência, em 1822, imagens da população e da nação emergem em diferentes veículos textos em geral, imprensa, artes gráficas e plásticas. Com a invenção da fotografia, na segunda metade daquele século, corpos negros no/do feminino proliferam e se replicam na paisagem cotidiana da Corte Imperial e explicitam os lugares configurados para sua representação na sociedade brasileira.

Segundo Alencastro, o Império é especialmente representado por meio de pinturas, aquarelas e gravuras, o que talvez tenha contribuído para agregar, na cultura marcadamente visual dos brasileiros de hoje, o período imperial ao passado colonial, empurrando o 'arcaísmo' monárquico para longe da 'modernidade republicana' (ALENCASTRO, 1997: p. 10). As imagens de uma "turba variegada de negros e negras" (SPIX \& MARTIUS, 1981: p. 48) se reproduzem nos quadros da monarquia e do cotidiano. Replicadas nos textos, elas demarcam localizações e hierarquizações no imaginário social também pela diferença designada no corpo e na pele, significativa do feminino, da raça e da condição civil do cativeiro, esta que foi reconhecida, mas também vivida e disseminada na experiência escravocrata até 1888 , e cinzelada na historiografia e na cultura para além dela.

Negro ou negra é uma designação que deve ser vista na espessura de sua historicidade. Em certos lugares, "preto" era empregado como sinônimo de africano e os índios eram reconhecidos como "pretos da terra". "Pretos" ou "crioulos" significavam a condição de escravo ou ex-escravo. Como observa Hebe Mattos, "durante todo o período colonial, e mesmo até bem avançado o século XIX, os termos 'negro' e 'preto' foram usados exclusivamente para designar escravos e forros" (MATTOS, 2000: pp.16-7).

As marcas da desigualdade se configuram, adensam e espraiam no imaginário social. No feminino, imprimem-se em corpos negros que, além daquele significado geral que remete à origem africana ou dela descendente, produzem sentidos específicos. Além de "racializados", portanto, são corpos sexuados, distribuem-se no território de sentidos e difundem uma conotação naturalizada que, quase indelével, refere-se à disponibilidade exacerbada: no oitocentos, para compra, venda, aluguel, para o trabalho incansável; antes e após 1888, para os serviços de limpeza, os cuidados da casa e do outro, para os prazeres da carne; até hoje, seus contornos podem insinuar a inclinação para a vida precária e a resistência - a pobreza, os salários indecentes -, tanto para a vida em "zonas inóspitas” da existência humana e social, quanto para práticas em

Dossiê Transversos: O Corpo na História e a História do Corpo, Rio de Janeiro, v. 05; n. 05; Ano 02. dez. 2015. 
esferas interditas do sexo fora da norma. Ou, como adverte Foucault, para as sexualidades periféricas. Imagens de mulheres negras podem ser consideradas elementos de inflexão no sistema de inteligibilidade cultural. (FOUCAULT, 1988.)

Embora talvez não se tenha exatamente pretendido falar delas na experiência da escravidão no Brasil monárquico, em seus corpos negros, sujeitos-objetos costumaram ser vistos na história/historiografia "em sua contribuição passiva" em meio aos povos "bárbaros ou semibárbaros", "de nível cultural ínfimo" (PRADO Jr.,1977: p. 278) e, assim, distribuem-se em uma miríade de discursos sociais. Suas imagens foram veiculadas em páginas da imprensa - anúncios de compra, venda, aluguel de bens imóveis e semoventes -; em textos da administração pública registros cartoriais; nas normas municipais reguladoras das ruas, do comércio, da saúde, e nos textos da monarquia constitucional - na legislação reguladora do trabalho e da passagem gradual para o trabalho livre. Também na literatura dos viajantes estrangeiros do século XIX - de naturalistas, cronistas, artistas -; na iconografia nos séculos XIX e XX; na literatura brasileira na prosa e poesia -; na historiografia e na memorialística do século XX.

Essas imagens são impactantes pelo que mostram e por aquilo que nelas não aparece de forma transparente ou literal: uma materialidade cultural constitutiva, funcional, em desdobras. Em suas características específicas, em suas qualidades singulares, de acordo com cada esfera e finalidade de comunicação, nos contornos sinuosos e estetizados dos corpos, no caso dos registros iconográficos, localizados em regiões sombrias, inóspitas ou inabitáveis da visualidade, ou produzidos na região de uma visibilidade inferiorizada e naturalizada.

Quando no feminino, eles não escondem uma história da sexualidade, da racialidade e da violência de relações sociais no Brasil. Dentre outros operadores da ordem do patriarcado escravocrata, o discurso social tratou de estetizar, romancear, estilizar, glamourizar as imagens, ou delas não lembrar, às vezes delas esquecer. E a replicação de algumas das mesmas imagens funciona para fazer operar jogos binários e assimétricos de significação, ainda que se consiga, em certas circunstâncias, apreender figurações de resistência ${ }^{4}$ (LAURETIS, 2007).

A historiografia, e também a iconografia, inclusive a fotografia, produziram a evidência do corpo-negro-mercadoria como fundamento, meio e objeto de atividades comerciais, do corponegro-patrimônio nas relações de bens, alienação e troca, de corpos-propriedades que representam, produzem a riqueza, e fazem operar poderes econômicos e sociais. Sua presença

4 Dados estatísticos sobre desigualdades de gênero e raciais no contexto da educação superior, mercado de trabalho e renda, em relação à pobreza, acesso a bens, exclusão digital e à violência, articuladas à situação de classe, geracional, regional permitem pensar mecanismos históricos da distribuição desigual socioeconômica, cultural e política na sociedade brasileira. Ver: MARCONDES, Mariana Mazzini et.al. (org.). Dossiê Mulheres Negras: retrato das condições de vida das mulheres negras no Brasil. Brasil: IPEA, 2013.

Dossiê Transversos: O Corpo na História e a História do Corpo, Rio de Janeiro, v. 05; n. 05; Ano 02. dez. 2015. 
ambivalente e disseminada no discurso também teve como efeito "uniões de pura animalidade", resultou na imagem de um povo "passivo" e "melancólico", costumou ora exibir, ora ocultar, a depreciação da raça (SCHWARCZ, 1993; RAGO, 1995). Tal presença faz operar poderes em movimento na dicotomia reiterada antes e depois da abolição, acionada também nos discursos da ciência e da arte, veiculada por meio de noções como de civilização x barbárie. Trata-se de uma presença que remete aos jogos históricos de (des)valorização da mestiçagem nos quadros do pensamento social brasileiro (MATTOS, 2000; CORRÊA,1998).

Corpos negros de mulheres expõem as marcas que os localizam em estratos inferiores da sociedade e os atrelam a seus destinos biológicos, historicamente construídos/formulados/entendidos no Brasil do oitocentos e, quiçá, em outras regiões do mundo atlântico. Exprimem identidades viabilizadas e qualificadas pelo sexo-gênero, pela raçaetnia e a condição civil/servil. Judith Butler contribui para a reflexão sobre as identidades procriadoras e nutrizes, ao considerar o sexo, não como

(...) simplesmente aquilo que alguém tem ou uma descrição estática daquilo que alguém é: ele é uma das normas pelas quais "alguém" simplesmente se torna viável, é aquilo que qualifica um corpo para a vida no interior do domínio da inteligibilidade cultural (... ) (BUTLER, 2000: p.155).

Nesses discursos, como no conjunto aqui apresentado, as imagens revelam corpos trabalhadores, úteis, recatados, mas, também, se considerados outros discursos ${ }^{5}$, corpos considerados transgressores, devassos ou viciosos. De um lado, imagens de quitandeiras, engomadeiras, lavadeiras, serviçais domésticas que se dão a ler em corpos que trabalham, de outro, corpos que resistem, se recusam a colaborar, ou que fogem do regime do cativeiro. A evidência de corpos cativos nos discursos sugere, particularmente, sua disponibilidade para o trabalho incansável, mas também para outras formas de dominação, para as práticas desregradas e descomprometidas da sexualidade e do prazer, que levavam à procriação. Entre esses, mais ou menos dóceis, controlados ou controláveis, ao procriarem, não era incomum que assumissem uma função específica na construção da desigualdade social como corpos de amas-de-leite e mãespretas...

E especificamente nesta função social, corpos de mulheres negras ganham especial destaque e visibilidade em álbuns, particularmente nos cartes de visite, ou seja, em imagens da família de elites proprietárias que se servem do trabalho daqueles e os expõem ou distribuem

5 Refiro-me ao discurso da medicina higiênica que condenava as práticas do aleitamento escravo e considerava as amas-de-leite mulheres "viciosas" a serem evitadas no seio da família e outros textos de moralistas e da imprensa do período que condenavam as práticas de sujeitos escravizados. Ver: "Preta com muito bom leite, prendada e carinhosa: cartografia das amas-de-leite na sociedade brasileira oitocentista (1850-1888). Tese de doutorado. Programa de Pós-graduação em História da Universidade de Brasília/UnB/2006.

Dossiê Transversos: O Corpo na História e a História do Corpo, Rio de Janeiro, v. 05; n. 05; Ano 02. dez. 2015. 
como sinal de distinção. Na ordem do patriarcado escravocrata, já no final do período monárquico, superexpostos no cenário do cotidiano, suas imagens assumem materialidade e eficácia discursiva, ao conferir sentidos próprios de um contraste e uma assimetria social, no jogo ambivalente das práticas sociais do Brasil monárquico e escravocrata.

\section{Representações, discursos, experiências, identidades: corpos em movimento...}

Com a abolição da escravidão em 1888, e a proclamação da República em 1889, corpos de mulheres são remodelados nos discursos da sociedade que se quer reinventar liberta das marcas da escravidão e, para isso, vislumbra o modelo da ciência, da civilização e do progresso. Experiências de mulheres negras reaparecem nos textos que circulam entre as elites letradas - nos jornais, nas teses de medicina e na literatura do período - e também na comunicação dispersa e cotidiana das imagens em circulação. Re-significadas, ao longo do século XX, na lírica de romancistas e poetas, em estudos históricos e sociológicos, corpos de "mães pretas" são reelaborados não mais para falar ou lembrar as práticas da escravidão, mas para neles serem insinuadas e sublinhadas as práticas da sexualidade que resultam na mestiçagem, esta que se torna alvo do discurso social. A mestiçagem, esta que se quer negar, recusar, branquear, positivar ou definitivamente esquecer seria atribuída à capacidade proliferadora daquelas mulheres, ou seja, do "ventre gerador" de outros corpos. Em seus corpos sinuosos e na pele negra, elas têm ressaltadas, ainda nos discursos sobre o cativeiro, certas habilidades singulares, tais como para as práticas do sexo, e também para uma espécie de liberdade metafísica que pressupõe o exercício de uma vida voltada para o outro, além da vocação para o sacrifício e a dor.

Trechos da literatura e da iconografia e discursos em geral evidenciam muitos corpos de mulheres menos respeitosos ou honrados, do que disponíveis para o prazer sexual, para o trabalho e a reprodução social mais ou menos higiênica. Eles consistem em materialidades que permitem produzir e enxergar significados e significações, na modelação de um lugar social que reafirma a "natureza" daquela existência subalterna. No momento das disciplinas, corpos de mulheres estão marcados pelos signos da negritude, do feminino e da escravidão, ou da origem africana. Parecem ainda confinados, levados a subsistir em um lugar simbólico que reitera a explicação biológica e justifica a destinação naturalizada e abjeta. Justifica?

Para além das ilusões da continuidade, sob a luz da problemática colocada pelas categorias sexo-gênero, raça-etnia, procuro imaginar, além de objetos-subjetividades, resistências; enxergar tensões e permanências; historicizar objetivações construídas sob matrizes androcêntricas que também resistem e insistem em tentar imobilizar as experiências naturalizadas do feminino e da negritude e seus sentidos. Trata-se de uma operação que implica reler as imagens discursivamente Dossiê Transversos: O Corpo na História e a História do Corpo, Rio de Janeiro, v. 05; n. 05; Ano 02. dez. 2015. 
tratadas na história e na memória social, e intervir em práticas e poderes historiográficos que estão em movimento.

O conjunto de retratos de amas-de-leite, mães-pretas, ou mulheres negras, se insere em uma coleção de imagens reunidas por terem circulado no Brasil do século XIX, mas não apenas ali. Sugere uma cartografia que revela aspectos da história/historiografia, e demonstra o jogo em funcionamento de uma desigualdade social - de sexo-gênero, raça, condição civil... Em meio ao conjunto maior de imagens de corpos que foram escravizados, femininos e masculinos, elas se referem ao cotidiano da escravidão, sistema que se imprime em corpos motrizes da vida econômica: da produção no campo - nas lavouras da monocultura e na subsistência - e nas cidades -, em um conjunto de outras funções do trabalho nas ruas e nos lares.

Elas aparecem em imagens do Brasil, não apenas no século XIX, como quitandeiras, lavadeiras, passadeiras, engomadeiras, cozinheiras, na singularidade do trato doméstico em geral, e nos cuidados com o outro, em particular. Essas imagens, particularmente em corpos apreendidos sob a perspectiva das representações sociais, expõem relações miúdas e tensões cotidianas; exibem detalhes e vetores sociais que revelam aquele "mais" de que fala Foucault, isto é, traços profundos da desigualdade e mecanismos históricos de dominação violenta que incidem na cultura, na vida psicológica, afetiva, elementos que não se dissiparam absoluta ou simplesmente com a abolição da escravidão...

São corpos significativos de uma materialidade construída em termos de uma "natureza passiva", "lasciva”, "emocional”, em traços cunhados para significar uma população pouco afeita ao trabalho e à civilização; corpos que, ao serem expostos, costumam conotar a população e a pátria, território matriz; ou identidades da nação e a configuração cultural singular, que, para o bem e para o mal, exprime-se por meio de ideias-imagens reveladoras da miscigenação desenfreada, reconstruída ora como nefasta, ora bem-quista na historiografia brasileira. Sem que se pretenda pressupor uma continuidade entre elas, as imagens do oitocentos coletadas até aqui sugerem uma ambivalência elementar e o trânsito sorrateiro e dissimulado de alguns sentidos: entre eles, apontam para a reprodução da família e do cativeiro; para as marcas indeléveis da negritude e o discursos do 'embranquecimento'; para as instituições modernas que se organizam em torno da nação promissora e para a permanência naquele período por muitos desejada da ordem escravista; para a geração do futuro e para a degeneração originária, física e simbólica, da nação escravocrata. (FLORES, 2007; RAGO, 1995 e 1998; PRADO Jr., 1977).

A emergência dessas imagens no discurso social do Brasil, por outro lado, revela a centralidade do corpo-imagem como significado-significante na espessura da representação ou das

Dossiê Transversos: O Corpo na História e a História do Corpo, Rio de Janeiro, v. 05; n. 05; Ano 02. dez. 2015. 
tecnologias da identidade, isto é, no sistema cultural ordenador dos sentidos (LAURETIS, IBID). A produção do corpo marcado por traços identitários e a criação/reiteração/classificação do elenco desses traços e efeitos evidencia a preocupação com a formulação de um alfabeto moderno da linguagem que também se organiza no campo da representação, da fotografia e da arte, enquanto contorna as tensões e poderes em movimento: nos registros textuais de viajantes e naturalistas, que cunharam descrições laboriosas da 'verdade' do que viram; de pintores, desenhistas e fotógrafos, narradores que não só produziram identidades de uma sociedade e um país como ensinaram a figurá-lo, a descrevê-lo, organizando para os olhos nativos e para a posteridade uma idealidade da paisagem social e o modo de defini-la (SUSSEKIND, 1990: pp. $39-40)$.

Ao modo da operação historiográfica, a partir de técnicas de produção e instrumentos que lhes são próprios e de um lugar social que torna possível a análise de documentos veiculados em certas condições de possibilidade (CERTEAU,2000; FARGE, 2011), a cartografia sugere reunir imagens-corpos-construtos, dimensões integrantes e integradoras da nação brasileira, identidades mobilizadas por/em diferentes discursos, dentre eles o historiográfico. A análise de uma iconografia historicamente localizada permite identificar regimes de visualidade no/do pensamento social brasileiro e da cultura ocidental. Assim, reunidas, as imagens conformam uma coleção e convidam à historicização, isto é, à crítica epistemológica que procura quebrar-lhes a naturalidade, o sentido de uma essência biológica, ou a-histórica (SPIVAK, 2010; HALL, 2001).

Trata-se de um desafio que consiste particularmente em recusar o corpo natural, evidência construída no âmbito da epistemé clássica que se dissemina no ocidente e na modernidade para orquestrar objetos e códigos da cultura; apreender a figuração do corpo como espectro articulador da linguagem, de esquemas perceptivos, de valores e hierarquias em suas práticas. Perseguir a construção de corpos negros no/do feminino nos registros históricos e operar no campo da crítica histórica das identidades e das representações sociais significa problematizar as imagens como construtos sociais em suas implicações afetivas, normativas, mentais, psicológicas e cognitivas, como produtos e processos de apropriação da realidade exterior ao pensamento e de elaboração social dessa realidade (JODELET, 2001).

Reler corpos-identidades-subjetividades na/da história em diálogos interdisciplinares com a arte, a comunicação, a filosofia, a literatura, entre outros discursos, é oportunidade para se especular, a propósito do objeto, sobre certos modos do olhar, de elaboração do saber-poder e do pensamento. Além disso, revisitar a cultura visual oitocentista para problematizar a construção dos corpos negros no/do feminino, localizá-los em sua circulação e dispersão histórica é uma 
maneira de, uma vez que se saiba como foram construídos, proceder à desnaturalização de imagens, documentos-monumentos, ou construtos, e à desconstrução de sentidos e, assim, invadir ou borrar alguns limites da cultura para tentar reconstruí-los sob outras bases e em outros termos (FOUCAULT, 2000).

\section{Referências Bibliográficas}

AlENCASTRO, Luiz Felipe (org.) NOVAES, F. A. (coord.) História da Vida Privada no Brasil 2. Império: a corte e a modernidade nacional. São Paulo: Companhia das Letras, 1997.

ANDERSON, Benedict. Comunidades Imaginadas. Reflexões sobre a origem e a difusão do nacionalismo. São Paulo: Companhia das Letras, 2008.

ANDRADE, Joaquim Marçal Ferreira. História da fotorreportagem no Brasil. Rio de Janeiro: Elsevier, 2004.

BARTHES, Roland. A Câmara Clara. Rio de Janeiro: Nova Fronteira, 1980.

BUTLER, Judith. Performative Acts and Gender Constitution. An Essay in Phenomenology and Feminist Theory. In: Writing the Body: Female Embodiment and Feminist Theory. Eds. Katie Conboy, Nadia Medina, Sarah Stanbury. New York: Columbia University Press, 1997.

Corpos que pesam: sobre os limites discursivos do "sexo". In: LOURO,

Guacira Lopes. O Corpo Educado. Pedagogias da Sexualidade. 2a ed. Belo Horizonte: Autêntica, 2000.

CERTEAU, Michel. A Escrita da História. 2. ed. Rio de Janeiro: Forense Universitária, 2000.

CORREAA, Mariza. As Ilusões da Liberdade: a Escola Nina Rodrigues e a antropologia no Brasil. Bragança Paulista: Edusf, 1998.

FARGE, Arlette. Lugares para a História. Coleção História e historiografia. Belo Horizonte: Autêntica, 2011.

FLORES, Maria Bernardete Ramos. Tecnologias e Estética do Racismo. Ciência e arte na política da beleza. Chapecó: Argos, 2007.

FOUCAUlT, Michel. História da Sexualidade. A vontade de saber. 13. ed. Trad. M.T.C. Albuquerque e J.A.G.Albuquerque. Rio de Janeiro: Graal, 1988.

Arqueologia do Saber. 6. ed. Trad. Luiz Felipe Baeta Neves. Rio de Janeiro: Forense Universitária, 2000.

Dossiê Transversos: O Corpo na História e a História do Corpo, Rio de Janeiro, v. 05; n. 05; Ano 02. dez. 2015. 
HALL, Stuart. A identidade cultural na pós-modernidade. 6 $6^{\mathrm{a}}$ ed. Rio de Janeiro: DP\&A, 2001.

JODELET, Denise. Representações sociais: um domínio em expansão. In: JODELET, D. (org.) As representações sociais. Rio de Janeiro: EdUERJ, 2001.

LARA, Silvia H. Sedas, panos e balangandãs: o traje de senhoras e escravas na cidade do Rio de Janeiro: o traje de senhoras e escravas na cidade do Rio de Janeiro e de Salvador (século XVIII). In: SILVA, Maria Beatriz Nizza da (org.). Brasil: colonização e escravidão. Rio de Janeiro: Nova Fronteira, 2000.

LAURETIS, Teresa de. Figures of Resistance. Essays in feminist theory. University of Illinois Press, 2007.

A tecnologia do gênero. In: HOLLANDA, Heloisa Buarque de (org.) Tendências e Impasses: o feminismo como crítica da cultura. Rio de Janeiro: Rocco, 1994.

LOURO, Guacira Lopes. O Corpo Educado. Pedagogias da Sexualidade. 2a ed. Belo Horizonte: Autêntica, 2000.

MATTOS, Hebe Maria. Escravidão e Cidadania no Brasil Monárquico. Rio de Janeiro: Zahar, 2000.

MARCONDES, Mariana Mazzini et.al. (org.). Dossiê Mulheres Negras: retrato das condições de vida das mulheres negras no Brasil. Brasil: IPEA, 2013. Acesso: 02/02/2014. Disponível em: http://www.ipea.gov.br/portal/images/stories/PDFs/livros/livros/livro_dossie_mulheres_negras. pdf.

PRADO Jr., Caio. Formação do Brasil Contemporâneo. São Paulo: Brasiliense, 1977.

RAGO, Margareth. As mulheres na historiografia brasileira. In: SILVA, Zélia Lopes de et al. (org.) Cultura Histórica em Debate. São Paulo: Unesp, 1995.

Sexualidade e identidade na historiografia brasileira. XIX Simpósio Nacional da Anpuh. História e Cidadania. Vol.1. São Paulo/SP: Anpuh/Humanitas/USP, 1998.

SAID, Edward. Cultura e Imperialismo. Trad. Denise Bottmann. São Paulo: Companhia das Letras, 2011.

SCHWARCZ, Lilia Moritz. O Espetáculo das Raças: cientistas, instituições e questão racial no Brasil 1870-1930. São Paulo: Companhia das Letras, 1993. 
SPIVAK, Gayatri Chakravorty. Pode o subalterno falar? Trad. S.R.G. Almeida; M.P.Feitosa; A.P. Feitosa. Belo Horizonte: UFMG, 2010.

SÜSSEKIND, Flora. O Brasil não é longe daqui: o narrador, a viagem. São Paulo: Companhia das Letras, 1990.

SPIX, J. B. \& MARTIUS, C. F. P. Viagem pelo Brasil 1817-1820. Vol. 1. Trad. Lucia F. Lahmeyer. Belo Horizonte, São Paulo: Itatiaia, Edusp, 1981.

\section{Como citar:}

CARNEIRO, Maria Elizabeth Ribeiro. Fotografia e História, a existência e o vestígio remanescente: corpos negros de mulheres no 'Teatro de Enunciados' do Brasil oitocentista. Revista Transversos. "Dossiê: O Corpo na História e a História do Corpo". Rio de Janeiro, Vol. 05, nº. 05, pp. 86-106, Ano 02. dez. 2015. Disponível em: <http://www.e-publicacoes.uerj.br /index.php /transversos >. ISSN 2179-7528. DOI: 10.12957/transversos.2015.19799. 